\title{
Encounters with the stone age
}

\section{John Launer}

Human beings have not been around for a very long time, relatively speaking. If you imagine that the earth - four thousand six hundred million years old - is a 46 year old person, then humans have been present for around 2 hours. As a species, one of our main attributes has been the ability to fashion tools and weapons out of stone, but in the last few minutes of geological time we have also acquired the knowledge to smelt metal: first copper, then bronze, and finally iron and steel. Most people think of the Stone Age as distant and primitive, but this is wrong in several ways. Stone tools continue to be used in a number of fields, including surgical scalpels made from volcanic obsidian. ${ }^{1}$ There are still isolated groups of people in remote parts of the world who have not invented metal implements, nor chosen to trade or barter for these. When left alone, such groups can thrive. ${ }^{2}$ There is no evidence that the skills needed for an aboriginal lifestyle are less sophisticated than those required for a modern one based on the use of metals, nor has there been any detectable evolutionary change in homo sapiens during the transition from one to the other. ${ }^{3}$ We are in fact more unified by our common use of tools and language - capacities that evolved synergistically and employ the same parts of the brain ${ }^{4}$ - than we are differentiated by our materials. It would probably be better to think of ourselves as living in a combined Stone and Iron Age.

Another common belief is that modern metal-based cultures have prevailed mainly because of superior technology and productiveness. Again, the historical record suggests otherwise. The principal reasons for the disappearance of most stone-working civilisations have in fact been genocide and epidemics. In the last half a millennium, the major cultures of the northern hemisphere have wiped out most indigenous ones, both intentionally through the use of firearms, and unintentionally by the spread of infection. Within thirty years of the arrival of Hernán Cortés in Mexico in 1521, for example, 80 per cent of the Aztec population had died either in battle or through smallpox, typhus, salmonella and other imported diseases. In the century following the

Correspondence to Dr John Launer, Postgraduate Medical Journal, London WC1B 5DN, UK; johnlauner@aol.com
British colonisation of Australia, up to 90 per cent of the existing inhabitants were killed either through murder or disease. When European explorers arrived in the fifteenth century in what is now the United States, there were around 10 million natives. By the beginning of the twentieth century there were fewer than 300 000. In some areas of the country, large numbers had died in atrocities carried out by Western settlers, but the majority succumbed to smallpox, measles, influenza, whooping cough, diphtheria, typhus, bubonic plague, cholera, scarlet fever, syphilis, tuberculosis and alcoholism.

\section{ISHI THE 'LAST WILD INDIAN'}

If the history of this cruel encounter between civilisations could be summed up in a parable, it would probably be the true story of a solitary native American who walked out of the north Californian forest on August 29th, 1911. In common parlance, he had literally walked out of the Stone Age. He appeared to be in his forties and was starving. He spoke a language that no-one, either white or native American, could understand. By good fortune, he was initially imprisoned rather than shot on sight, which had been the common fate of most of the natives in that state. Even more exceptionally, his existence soon came to the notice of two anthropologists at the University of California named TT Waterman and Alfred Kroeber.

Recognising that the man would certainly need protection, and might also offer them a last opportunity to study a truly "wild Indian," they removed him to the museum of anthropology in San Francisco, where he became a resident and a subject for research. He stayed there for the remainder of his life. Although he never revealed his name - an act that would have signified excessive intimacy in his own culture - he agreed to be known as Ishi, a generic word in his language for 'man.' Because of the way that Waterman, Kroeber and their colleagues carried out their work, we possibly know more about life in the pure Stone Age from Ishi than we do from any other individual. Along with the documentation of their researches, ${ }^{5}$ a sensitive biography of Ishi written by Kroeber's wife Theodora, herself an anthropologist, ${ }^{6}$ and a more recent volume edited by their sons ${ }^{7}$, offer us an understanding of what it was like to leave behind a world that had quite literally died, and to enter modernity instead.

Ishi, it turned out, was the sole surviving member of a small tribe named the Yahi, who had inhabited the rocky and heavily forested foothills and canyons on the slopes beneath Mount Lassen. He had spent his entire life in hiding from the gangs of prospectors, ranchers, bounty-hunters and thieves who had gradually encroached in the hills, capturing or exterminating natives as they advanced. Once a tribe that numbered in the hundreds or even a few thousand, by the time of Ishi's birth they had been reduced possibly to dozens by violence and disease. Further massacres, some of them gleefully and gruesomely recorded in the diaries and newspaper reports of local whites, eventually brought the number down to a band of four: Ishi, his sister and mother, and an uncle. For more than a decade, they had concealed themselves on a nearly inaccessible rock ledge. Finally, in 1908 a party of whites discovered it and looted all their hunting and cooking implements as souvenirs. For three of these last Yahi survivors, the theft was a death sentence by starvation. Ishi managed to fend for himself on his own for a further 3 years until giving himself up at - of all ironic places - a white man's slaughterhouse.

\section{TEACHING NATIVE SKILLS}

As Ishi's custodians learnt to understand some of his language, and he in turn acquired a degree of proficiency in English, he began to demonstrate and teach native skills including fire making, harpooning fish, stone knapping, bow construction, hunting, hut building and singing. $\mathrm{He}$ quickly mastered the use of metal tools including the hammer, saw and vice, and he incorporated glue into his work kit for feathering arrows, cementing bindings, and joining sinews for bow strings. In time, he was employed as a paid janitor in the museum. There are wonderful photos of him at work (see figure 1), and recordings of his voice. Sadly, moving film of him has not survived intact.

Written accounts by those who knew him convey an impression of even-temperedness, modesty, courtesy and friendliness. 'Ishi had kept his morale through grief and absolute solitariness; the impact of civilisation could not budge it,' Mrs Kroeber later wrote, using her husband's notes from the time. 'Beneath the shyness and reserve, he remained possessed of a natural, tempramental and unimpaired outgoingness and interest in people and phenomena, which he was able, day by 


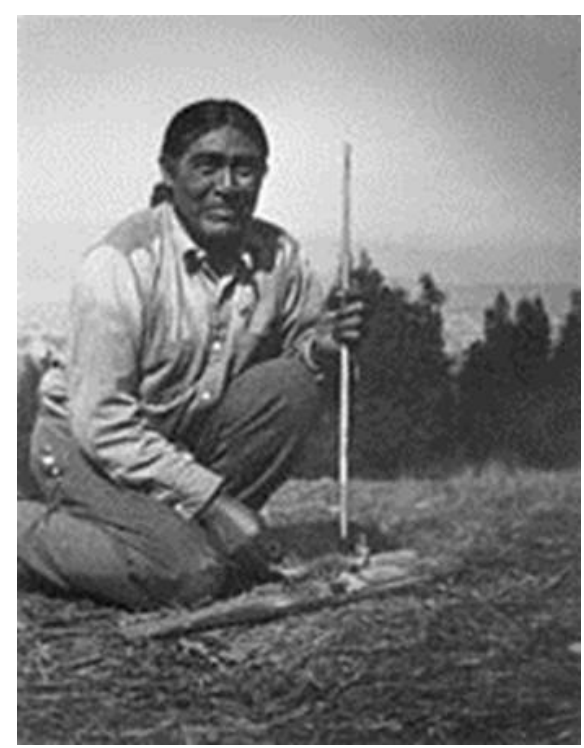

Figure 1 Ishi making fire.

day, to express ever more spontaneously.' (pp.125-6) He learnt to use money, read a clock, sign cheques and recognise the numbers on trams. He came to enjoy San Francisco's ferries and streetcars, not to mention shopping, cooking, and archery practice in Golden Gate Park. The vaudeville theatre, however, left him cold, and he preferred just to watch the audience. We can only speculate on his inner thoughts as he contemplated the kind of civilisation that had entirely displaced his own so traumatically.

As was probably inevitable, Ishi did not survive for many years. In 1915 he began to have fevers and lose weight, showing the obvious signs of tuberculosis. With the typical low immunity of aboriginal people to foreign microbes, he deteriorated rapidly, although he never complained, or spoke of his suffering or death. In March the following year. he had a very large pulmonary haemorrhage. He died, as was customary in such circumstances, following a very large dose of morphine.

His closest friend by that time was a doctor named Saxton Pope, who had learnt some of the ancient techniques of forest hunting from Ishi and had accompanied him, along with Waterman and Kroeber, on an expedition back to his original homeland beneath Mount Lassen. At his death, Pope wrote:

He closes a chapter in history. He looked on us as sophisticated children - smart, but not wise. We knew many things, and much that is false. He knew nature, which is always true. His were the qualities of character that last forever. He was kind; he had courage and self-restraint, and though all had been taken from him, there was no bitterness in his heart. His soul was that of a child, his mind that of a philosopher. [pp.237-238]

This epitaph on Ishi serves as a poignant commentary on past and present ages, and the encounter between the two.

Funding The authors have not declared a specific grant for this research from any funding agency in the public, commercial or not-for-profit sectors.

Competing interests None declared.
Patient consent Not required.

Provenance and peer review Not commissioned; internally peer reviewed.

(c) Author(s) (or their employer(s)) 2018. No commercial re-use. See rights and permissions. Published by BMJ.

\section{Check for updates}

To cite Launer J. Postgrad Med J 2018;94:731-732.

Received 26 December 2018

Accepted 26 December 2018

Postgrad Med J 2018;94:731-732.

doi:10.1136/postgradmedj-2018-136373

\section{REFERENCES}

1 Shadbolt P, 2015. How stone age blades are still cutting it in modern surgery. Available: https://edition.cnn.com/ 2015/04/02/health/surgery-scalpels-obsidian/index.html [Accessed 18 Nov 2018].

2 Survival International, 2018. The most isolated tribe in the world? Available: https://www.survivalinternational. org/articles/3101-the-most-isolated-tribe-in-the-world [Accessed 18 Nov 2018].

3 Gorman A, 2018. Why we should stop using 'Stone Age' to describe early humans. Available: https:// www.independent.co.uk/news/science/stone-ageearly-humans-australia-archaeology-aboriginalindigenous-people-a8518056.html [Accessed 18 Nov 2018].

4 Stout $\mathrm{D}$, Chaminade T, tools S. Stone tools, language and the brain in human evolution. Philos Trans $R$ SOC Lond B Biol Sci 2012;367:75-87.

5 Heizer RF, Kroeber T. Ishi the last Yahi: a documentary history. University of California Press: Berkeley CA, 1979

6 Kroeber T. Ishi in two worlds: a biography of the last wild Indian in North America. University of California Press, 1961.

7 Kroeber K, Kroeber C. Ishi in three centuries. Lincoln NE: University of Nebraska Press, 2008 